evaporated until it is sufficiently concentrated; in this state it will easily restore the blue color of reddened paper, and will give abundant precipitates with the chloruret of platina and the perchloric acid, as would a concentrated solution of the carbonate of potash. The use of these re-agents would be accompanied even with a well-marked effervescence.

I should not recommend pushing the experiment further, and treating, for example, the mass already exhausted by alcohol with water or acetic acid, be. cause, while acknowledging that by their means we might dissolve a certain quantity of potash, which had been used as a poison, it is certain that we should also dissolve a considerable quantity of the salts of potash naturally contained in the animal liquids and in food, so that we should run the risk of committing serious errors, in attributing to potash taken as a poison, re-actions due to the salts of potash naturally in the system. It were a hundred times better not to seek to separate the entire of the potash which has acted as a poison.-Journ. de Chimie Médicale.

\section{CASE OF MONSTROSITY.}

\section{TO THE EDITORS OF THE PROVINCIAL MEDICAL} JOURNAL.

Gentlemen, - If you think the following case worthy of record in your valuable Journal, I shall be gratified by its insertion.

I am, Gentlemen,

Your obedient servant, W. B. SANDERSON.

Ipswich, June 27, 1842.

November 29,1841 . I was called to Mrs. L., aged thirty-six, who has been married fourteen years, and was in labour of her first child. I found the os uteri well dilated, and the membranes protruding largely, through the volume of which I was unable to ascertain the presentation. I, therefore, ruptured them, and a large quantity of the liquor amnii escaped; when, on several further examination, with much puzzling and difficulty, I diagnosed an acephalous fœtus, by feeling the craggy edges of the base of the cranium, surrounding a soft, pulpy mass, which occupied the site of the brain. This proved a correct opinion on delivery, when $I$ received a complete monstrosity, presenting the extraordinary aspect of two distinct and perfect faces, united to one cranial base, and possessing four perfect and lucid eyes, two noses, two mouths, each divided by a septum, with a separate tongue and gums, and two chins; the rest of the body normal, well formed, and of good average size; one ear only on each side of the cranial base.

On viewing the posterior part of the trunk, I obsèrve (for I possess the curiosity) the spinal column deficient in the spinous processes of the vertebræ, the chord and its membranes exposed superficially, and the transverse processes widely separated throughout their whole length, until they unite at the sacrum.

On opening the thorax and abdomen, $I$ found their contents perfectly normal. I did not trace the faucial, œsophageal, or bronchial formations, being unwilling to disfigure my preparation so much as such an in. vestigation would involve.
I may add, it is a female child, and the mother felt its powerful movement a short time prior to delivery. Respiration never occurred.

\section{ON SPONTANEOUS FRACTURE OF THE THIGH-BONE.}

By Jonathan Toogood, Esq.

Senior Surgeon to the Bridgwater Infirmary.

In the course of my practice, two cases have occurred in which the thigh has been fractured without any external violence. The first was that of a man who had for many years been in a weak, nervous, and half paralytic state. In attempting to turn in bed, the bone broke. The case was considered an extraordinary one ; it was treated in the usual way, and united after a considerable time, and he lived many years after. The next case was that of James Pople's wife, of Bawdrip, aged fifty-five, who had been long in an infirm state of health, which terminated ultimately in paralysis of the lower extremities. She had suffered very severe pain in her right thigh for some months, which was considered by those about her to be rheumatic; and being a poor woman without friends, little was done for her relief. One evening, on being lifted up in the bed, the bone suddenly snapped; she was aware of it immediately, and cried out that her thigh was broken, but no one believed her, and she lay all that night in dreadful agony, but when, on the following morning, her neighbours saw the limb almost doubled by the viulent spasmodic action of the muscles which drew the ends of the bones forcibly against each other, I was requested to see her. Her condition was indeed truly deplorable, and the grating of the bones against each other was distinctly heard.

The limb was placed in splints, and united after a longer period than usual. I mentioned this case to Sir:Astley Cooper, who considered it to be cancer of the bone, and directed my attention to the state of the breasts, in both of which I discovered on examination several hard, knotty tumors, of a carcinomatous character.

The following interesting account of a similar accident will be found in the life of Archbishop Secker :-

"About a year and a half before he died, after a fit of the gout, he was attacked with a pain in the arm, near the shoulder, which, having continued about a twelvemonth, a similar pain seized the upper and outer part of the opposite thigh, and the arm soon became easier. This was much more grievous than the former, as it quickly disabled him from walking, and kept him in almost continual torment except when he was in a reclined position. During this time he had two or three fits of the gout, but neither the gout nor medicines alleviated these pains, which, with the want of exercise, brought him into a general bad habit of body.

On Saturday, the 30th of July, 1768, he was seized, as he sat at dinner with a sickness at his stomach. He recovered himself before night, but the next evening, whilst his physicians were attending, and his servants raising him on his couch, he suddenly cried out that his thigh-bone was broken. The shock was so violent that the servants perceived the couch to shake under him, and the pain so acute and unexpected, 
that it overcame the firmness he so remarkably possessed. He lay for some time in grcat agonies, but when the surgeons arrived, and discovered with certainty that the bone was broken, he was perfectly resigned, and never afterwards asked a question about the event. A fever soon ensued; on Tuesday he became lethargic, and continued so till about five o'clock on Wednesday afternoon, when he expired with great calmness in the 75th year of his age.

On examination, the thigh-bone was found to be carious about four inches in length, and at nearly the same distance from its head. The disease took its rise from the internal part of the bone, and had so entirely destroyed its substance, that nothing remained at the part where it was broken but a portion of its outward integument; and even this had mapy perforations, one of which was large enough to admit two fingers, and was filled up with a fungous substance, arising from within the bone. There was no appearance of matter about the caries, and the surrounding parts were in a sound state. It was apparent that the torture which his grace underwent during the gradual corrosion of this bone, must have been inexpressibly great. Out of tenderness to his family he seldom made any complaint to them, but to his physicians he frequently declared his pains were so excruciating, that unless some relief could be procured he thought it would be impossible for human nature to support them long; yet he bore them for upwards of six months with astonishing patience and fortitude, sat up generally the greater part of the day, admitted his particular friends to see him, mixed with his family at the usual hours, sometimes with his usual cheerfulness, and except some very slight defects of memory, retained all his faculties and senses in their full vigour till within a few days of his death."

In the second part of the 15 th voi. of the MedicoChirurgical Transactions, two cases of fracture of the thigh-bone taking place, without any violence, in connection with cancer, are related by $\mathrm{Mr}$. Salter, of Poole, in one of which an examination was afforded after death, and his description of the condition of the bone corresponds very much with that of the preceding case. I regret that no examination could be obtained in the case of James Pople's wife.

\section{DISLOCATION OF THE HIP, WITII FRAC-} TURE OF THE ACETABULUM.

\section{By Mr. Toogood.}

Thomas Rich, a sawyer, aged thirty, fell into a sawpit from a piece of timber, and received a violent blow on the hip from the heavy body which followed him. The head of the thigh-bone was thrown on the dorsum of the ilium, and the dislocation was reduced in the usual way without much difficulty. On the following evening it was evident that the head of the bone was not in its proper situation; the limb was shortened and somewhat inverted, presenting just the appearance of a dislocation into the ischiatic notch. Moderate extension, however, easily brought the leg of equal length with the other, and the whole limb to a natural state. He had retention of urine. The next day the limb was found again shortened, and although there was great swelling from the violent contusion which so heavy a body had occasioned, an accurate examination satisfied me that the head of the bone was still lying on the dorsum of the ilium. I was not present when the dislocation was reduced, but the surgeons who attended the patient wcre positive that they heard the bone return to its socket, and their opinion was confirmed by the patient and the bystanders. A careful examination was again made, when a fracture of the acetabulum was detected, which allowed the head of the bone to escape, and explained at once the cause of the limb presenting such different appearances. There was not the slightest difficulty in returning the bone to its natural position, but it was no easy matter to keep it there. 'l'his, however, was effected by fixing the pelvis, and keeping up permanent extension by means of a pulley. By persevering in this plan for several weeks the patient perfectly recovered the use of the limb.

I have frequently employed permanent extension by the pulley, in cases of very oblique or complicated fractures of the thigh, with the best effects, and particularly in one I attended about a year since, in which the shaft of the bone was broken in three different places, so that it was impossible to keep the limb right in any other way. The patient has an excellent limb, without any deformity.

Bridgwater, June, $184 \%$.

\section{ARTIFICIAL PREMATURE LABOR.}

TO THE EDITORS OF THE PROVINCIAL MEDICAL JOURNAL.

Gentremen,--If you think any useful hints will be given, or any practical suggestions offered to the profession, by republishing a case in which Dr. Lee induced abortion, together with a case which lately occurred in my own practice, I will trouble you to give them a place in your Journal.

\section{Yours, \&c.}

W. Allison.

In the "Lancet," June 18, 1842, at page 413, a case is related in which the membranes of the ovum were punctured in the fourth inonth of pregnancy, to arrest fever, epigastric pain, and incessant vomiting; immediately after which the fever and pain subsided and the vomiting ceased, though the fœtus was not expelled until after several weeks.

CASE.-M rs. J., of Retford, a delicate woman, aged 33, miscarried (about the six th week) towards the end of 1841. In January, 1842, she became pregnant of her fourth child; I first saw her on that occasion on the 10th of January, on account of a colored discharge, with debility. The hæmorrhage returned frequently until the 7 th of June, when it became so copious (in the fifth month) as to justify my endeavour to procure abortion. I passed a thick probe through the os uteri and the membranes, until $I$ felt my fingers wetted with the liquor amnii; after which she had a few pains. From that time there was scarcely any colored discharge-mercly a frequent oozing of water, with occasional pains. On the 20th, as she became anxious to be relieved from suspense, I passed the probe again without finding that I had increased the watery discharge. On the morning of the 26th, at five o'clock, 